\title{
ARTICLE
}

Received 19 Dec 2013 | Accepted 14 May 2014 | Published 17 Jun $2014 \quad$ DOl: 10.1038/ncomms5113

\section{A synthetic biochemistry molecular purge valve module that maintains redox balance}

\author{
Paul H. Opgenorth', Tyler P. Korman ${ }^{1} \&$ James U. Bowie ${ }^{1,2}$
}

The greatest potential environmental benefit of metabolic engineering would be the production of high-volume commodity chemicals, such as biofuels. Yet, the high yields required for the economic viability of low-value chemicals is particularly hard to achieve in microbes owing to the myriad competing biochemical pathways. An alternative approach, which we call synthetic biochemistry, is to eliminate the organism by constructing biochemical pathways in vitro. Viable synthetic biochemistry, however, will require simple methods to replace the cellular circuitry that maintains cofactor balance. Here we design a simple purge valve module for maintaining NADP + /NADPH balance. We test the purge valve in the production of polyhydroxybutyryl bioplastic and isoprene-pathways where cofactor generation and utilization are unbalanced. We find that the regulatory system is highly robust to variations in cofactor levels and readily transportable. The molecular purge valve provides a step towards developing continuously operating, sustainable synthetic biochemistry systems.

\footnotetext{
${ }^{1}$ Department of Chemistry and Biochemistry, UCLA-DOE Institute for Genomics and Proteomics, Molecular Biology Institute, University of California, Los Angeles, California 90095-1570, USA. ${ }^{2}$ Boyer Hall, UCLA, 611 Charles E Young Drive East, Los Angeles, California 90095-1570, USA. Correspondence and requests for materials should be addressed to J.U.B. (email: bowie@mbi.ucla.edu).
} 
$\mathrm{M}$ etabolic engineering and synthetic biology have been employed for the production of high-value chemicals but has not been as successful in meeting the stringent economics of large-scale commodity chemical manufacturing ${ }^{1}$. Microbial systems are often hampered by a variety of technical challenges that make it hard to achieve cost competitiveness, including poor yields owing to competing pathways; low productivity caused by slow growth rates or difficulties in pathway optimization; contaminating microbial growth; product toxicity; and expensive product isolation ${ }^{2,3}$.

Another approach that is beginning to receive attention is to perform complex biochemical transformations using mixtures of enzymes in a reaction vessel rather than within a cell. Building single, dedicated pathways in vitro can eliminate side reactions that occur in the cell, so that nearly $100 \%$ yields and fast reaction times are possible ${ }^{3-5}$. In vitro biochemical systems also allow for more precise control over optimization and product toxicity problems can be more easily diagnosed and mitigated ${ }^{6,7}$. Moreover, product extraction can be more facile.

Traditionally, in vitro pathway construction has been relegated to use as a research tool or in applications that require only $1-3$ enzymes for the production of chiral compounds and other highvalue chemicals ${ }^{1,8,9}$. Improvements in protein expression and access to stable enzymes have made more complex systems possible, however ${ }^{1,9-12}$. In vitro biotransformation systems have been reported in recent years involving systems of over 30 enzymes $^{13,14}$. One of the first modern studies in this area was an artificial pathway that produced hydrogen from starch ${ }^{1,15-17}$. The concept was recently advanced with a creative system that generated hydrogen from cellobiose at nearly $100 \%$ yields ${ }^{16}$. In another effort, hyper-thermophilic glycolysis enzymes were heterologously expressed, heat purified and assembled to convert glucose to $n$-butanol in $82 \%$ yield $^{18}$. In another study, an elegantly simplified non-phosphorylative Entner-Doudoroff pathway from hyper-thermophilic archaea was constructed to produce ethanol and isobutanol in $\sim 55 \%$ yields ${ }^{19}$. These pioneering studies illustrate the flexibility of synthetic biochemistry and the potential for high yields.

A limiting feature of earlier work in synthetic biochemistry systems is the need to either feed the systems with high-energy cofactors, or if they are generated by the pathway in situ, balance their use to ensure regeneration. For example, in the Sieber pathway to generate ethanol and isopropanol from glucose ${ }^{19}$, the pathway was beautifully designed to reduce only 2 mol of $\mathrm{NAD}^{+}$ to NADH during the catabolic phase and to reoxidize $2 \mathrm{~mol}$ of $\mathrm{NADH}$ in the anabolic phase. Thus, the utilization of $\mathrm{NAD}^{+}$was perfectly balanced allowing multiple passes through the pathway. In other systems, the pathways were also designed to maintain cofactor balance ${ }^{18}$.

The requirement for perfect balance limits synthetic biochemistry in two ways, however. First, it places stringent constraints on pathway design, potentially limiting the types of chemicals that can be made. Second, it may ultimately limit the number of cycles the system can perform without adding additional, expensive high-energy cofactors. Why? If there is any spontaneous oxidation of $\mathrm{NADH}$, it effectively creates an unintended cofactor imbalance because more $\mathrm{NADH}$ is required than would be expected based on the stoichiometry of the system. Thus, over time the levels of NADH will dissipate and the system will wind down. As the economic viability of a synthetic biochemistry system will likely depend on the ability to run the systems in a self-sustaining manner for long periods of time, we need to develop methods that can maintain high-energy cofactor levels without requiring perfect pathway stoichiometry.

Ideally, we believe that a synthetic biochemistry system should be able to generate more high-energy cofactors in the catabolic phase of the pathway, than is needed in the anabolic phase of the pathway so that gradual losses by spontaneous ATP hydrolysis or $\mathrm{NAD}(\mathrm{P}) \mathrm{H}$ oxidation can be tolerated. On the other hand, if an excess of high-energy cofactors is produced, it is necessary to also find a way to dissipate excess production so that the reactions can proceed (that is, carbon flux can be maintained). In short, we need a way to maintain cofactor balance. If it were possible to regulate cofactor balance without affecting carbon flux, it would also allow for much more flexibility in pathway design. As a step towards this goal, we describe a synthetic biochemistry purge valve module to maintain the proper balance of NADPH and test whether this general approach can be applied for the production of the bioplastic polyhydroxybutyrate (PHB) and isoprene.

PHB and other polyhydroxyalkanoates (PHAs) are biodegradable thermoplastics. PHAs can have characteristics similar to many popular petrochemical-derived polymers, but are nontoxic and biodegradable, so they are attracting increased attention as a possible green alternative to petroleum-based polymers in a wide range of applications ${ }^{20-22}$. The best characterized and most abundant PHA polymer is PHB that is naturally produced from acetyl-CoA as a carbon and energy storage mechanism in many organisms ${ }^{22}$. Currently, industrial production of PHB is done by in vivo batch culture processes under nutrient starvation. This process is typically very time consuming, requires large fermentation volumes and requires expensive methods for the extraction of $\mathrm{PHB}^{20}$. Prior attempts to produce bioplastic in vitro have required the addition of sacrificial substrates and a molar excess of cofactors to convert acetate to $\mathrm{PHB}^{23}$.

Isoprene is a platform chemical for a variety of products, but it is mostly employed in the production of synthetic rubber ${ }^{24-26}$. The isoprenoid pathway also provides precursors for over 25,000 known biomolecules including drugs such as taxol and potential biofuels $^{27}$. There have been a number of efforts to produce isoprene in microorganisms $\mathrm{s}^{24,26,28,29}$ and the best reported yield is $28 \%$ from glucose ${ }^{24}$. We recently showed that a synthetic biochemistry system could produce isoprene in $>95 \%$ yield from pyruvate as long as high-energy cofactors were added ${ }^{30}$.

Here we employ a purge valve system in a pathway to convert pyruvate into PHB that maintains sustainable reducing cofactor balance, without the requirement for perfect stoichiometric matching of cofactor generation and carbon usage. Further, we show that our purge valve module can be used as the basis for the production of other acetyl-CoA-derived products by applying it to the production of isoprene from pyruvate via the mevalonate pathway. Regulatory modules such as this can free us from having to perfectly balance cofactor utilization when designing synthetic biochemistry systems.

\section{Results}

Overview and design of pathway. The biotransformation of pyruvate into PHB illustrates a basic cofactor imbalance problem that is encountered in biochemical systems. In particular, conversion of pyruvate to acetyl-CoA by pyruvate dehydrogenase (PDH) yields one molecule of NADH. However, the threeenzyme pathway (phaA, B and C) to PHB from acetyl-CoA utilizes only one half of a molecule of NADPH per acetyl-CoA. Thus, the canonical pathway produces an excess of reducing equivalents. Moreover, the reducing equivalents are of the wrong type (NADH rather than $\mathrm{NADPH})$. We therefore designed a pathway, shown in Fig. 1a that can generate the correct cofactor and regulate its production.

In our design, we create a synthetic biochemistry 'purge valve' that effectively decouples the stoichometric production of $\mathrm{NAD}(\mathrm{P}) \mathrm{H}$ from acetyl-CoA (Fig. 1). To this end, we employ a mixture of both an $\mathrm{NAD}^{+}$-utilizing wild-type (WT) $\mathrm{PDH}$ 


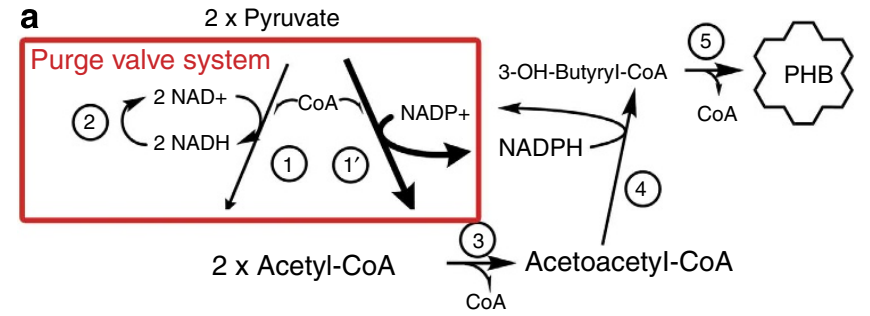

b
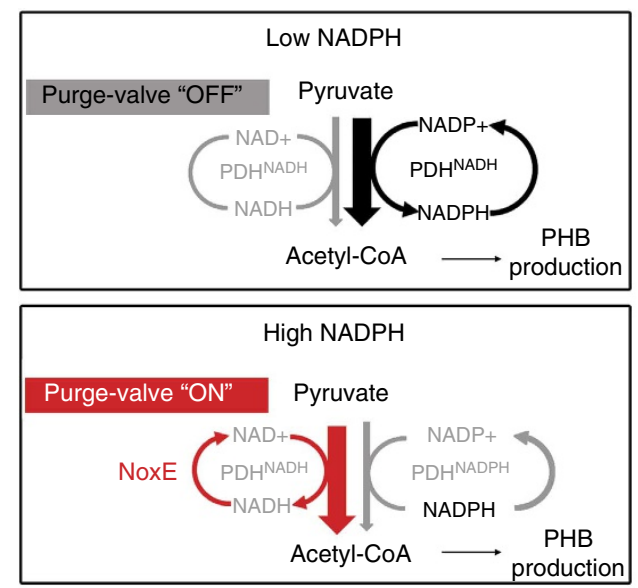

C

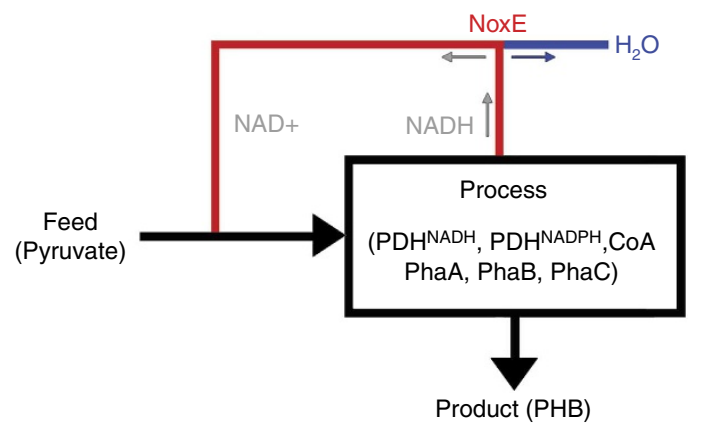

Figure 1 | A synthetic biochemistry purge valve system for the production of PHB. (a) The in vitro metabolic pathway for the conversion of pyruvate to PHB. The pathway consists of six separate reactions: reaction 1 $\left(\mathrm{PDH}^{\mathrm{NADH}}\right)$, reaction $1^{\prime}\left(\mathrm{PDH}^{\mathrm{NADPH}}\right)$, reaction 2 (NoxE), reaction 3 (PhaA), reaction $4(\mathrm{PhaB})$ and reaction $5(\mathrm{PhaC})$. The purge valve is highlighted in the red box. (b) How the purge valve is designed to function. At low $\mathrm{NADPH}$ (high NADP +), PDH ${ }^{\mathrm{NADPH}}$ reaction dominates, generating acetyl-CoA and NADPH from pyruvate and NADP ${ }^{+}$. The purge valve is effectively 'off'. In high-NADPH (low NADP ${ }^{+}$) conditions, the PHDNADPH enzyme is starved for oxidized cofactor, shutting down this pathway to acetyl-CoA. In this situation, the $\mathrm{PDH}^{\mathrm{NADH}} / \mathrm{NoxE}$ system takes over, producing only acetyl-CoA. In other words, the purge valve is effectively 'on'. (c) A chemical engineering schematic of the purge valve system used in the production of PHB from pyruvate, involving a cofactor recycle loop.

$\left(\mathrm{PDH}^{\mathrm{NADH}}\right)$, a mutant $\mathrm{PDH}$ that utilizes $\mathrm{NADP}^{+}\left(\mathrm{PDH}^{\mathrm{NADPH}}\right)$, and a water-generating NADH oxidase (NoxE) that specifically oxidizes $\mathrm{NADH}$, but not $\mathrm{NADPH}^{31,32}$. By employing this metabolic node, we generate NADPH needed for PHB production from pyruvate, but also dissipate excess reducing equivalents in an autoregulatory manner. As illustrated in Fig. 1b, under low-NADPH, high-NADP ${ }^{+}$conditions, the mutant $\mathrm{PDH}^{\mathrm{NADPH}}$ can operate to generate acetyl-CoA and restore NADPH levels. Under high-NADPH, low-NADP ${ }^{+}$conditions, the PDH ${ }^{\mathrm{NADPH}}$ activity will automatically be choked off, and the WT $\mathrm{PDH}^{\mathrm{NADH}}$ will be used preferentially to produce acetyl-CoA

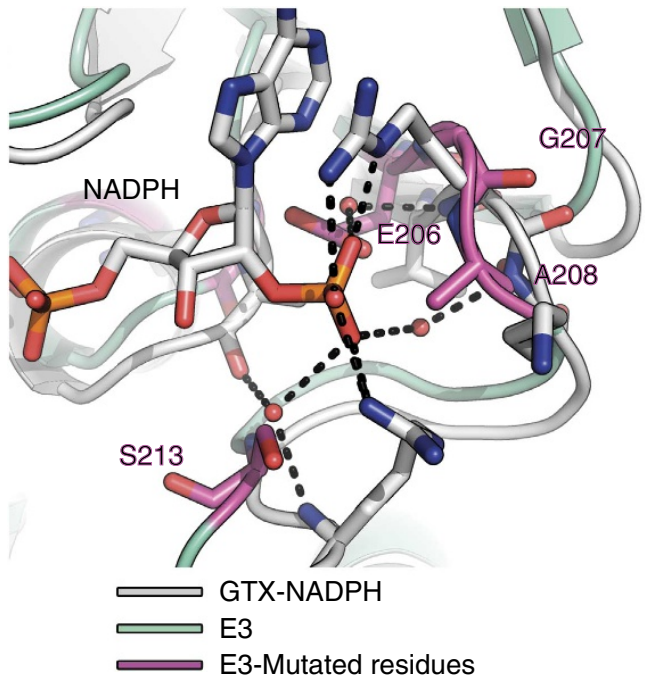

Figure 2 | Design of the PDH ${ }^{\text {NADPH }}$ enzyme. The structures of the wildtype G. stearothermophilus E3 subunit (E3, green backbone trace) is shown overlaid on the structure of $E$. coli glutathione reductase (GTX-NADPH, grey backbone trace). The NADPH substrate from glutathione reductase is shown in stick representation, showing the placement of the phosphate moiety that needs to be accommodated. The residues changed to accept the phosphate (E206V, G207R, A208K and S213R) are shown in purple.

and NADH. In this high-NADPH condition, the reducing equivalents are not needed. Because the reducing equivalents are produced in the form of NADH and not NADPH, they are eliminated by the oxidase, NoxE. The presence of NoxE ensures that NADH never builds up and the $\mathrm{PDH}^{\mathrm{NADH}}$ can always operate to generate carbon for the PHB pathway in the form of acetyl-CoA. The $\mathrm{PDH}^{\mathrm{NADH}} / \mathrm{PDH}^{\mathrm{NADPH}} / \mathrm{NoxE}$ system acts like a purge valve that opens under conditions of high NADPH to relieve the excess reducing equivalent 'pressure' (that is, buildup of $\mathrm{NADH}$ ) and allow carbon flux to be maintained. An engineering schematic of the purge valve system is shown in Fig. 1c.

Enzyme engineering and cofactor specificity. To implement our purge valve module, we needed an $\mathrm{NADP}^{+}$-utilizing $\mathrm{PDH}$. A mutant of Escherichia coli PDH has been engineered to have $\mathrm{NADP}^{+}$specificity by introducing mutations into the $\mathrm{E} 3$ enzyme $(\mathrm{EcE} 3)^{33}$. The E. coli PDH proved too unstable for our system, however. We therefore engineered a mutant of the thermophilic Geobacillus stearothermophilus PDH that preferentially accepts $\mathrm{NADP}^{+}$with increased enzyme stability.

Similar to the design of the E. coli PDH mutant, the G. stearothermophilus PDH mutant was designed by overlaying the known structure of the G. stearothermophilus E3 subunit $(\mathrm{GsE} 3)^{33}$ with the known structure of the related E. coli glutathione reductase, which utilizes $\mathrm{NADP}^{+}$(ref. 33) (REF or PDBID:1GET). The structural superposition allowed us to position the additional phosphate moiety in the active site of the GsE3, based on how it was placed in glutathione reductase (see Fig. 2). We could then design side-chain substitutions in GsE3 that might allow acceptance of the phosphate. We were guided by the prior successful design of the EcE3 enzyme, which shares $47 \%$ sequence identity with the GsE3 (refs 33,34). The mutations introduced into EcE3 were E206V, G207R, A208K, G209H and S213R (GsE3 numbering). After examining the changes in the context of the GsE3 structure, we decided to introduce all but G209H, because it appeared that the new His side chain might create steric clashes with nearby K224 and N237 residues. 
The kinetic properties of the engineered and WT enzymes reveal that the mutations alter specificity as desired. The kinetic parameters are listed in Supplementary Table 1. For the WT G. stearothermophilus enzyme $\left(\mathrm{GsPDH}^{\mathrm{NADH}}\right), k_{\mathrm{cat}}$ is 11.2 times higher with $\mathrm{NAD}^{+}$than $\mathrm{NADP}^{+}$and $k_{\text {cat }} / K_{\mathrm{m}}$ is 1,150 times higher. For the engineered mutant $\left(\mathrm{GsPDH} \mathrm{NADPH}^{\mathrm{N}}\right), k_{\text {cat }}$ is 7.3 times higher with $\mathrm{NADP}^{+}$than NAD + and $k_{\mathrm{cat}} / K_{\mathrm{m}}$ is 21 times higher. Thus, we were able to flip the specificity of the $\mathrm{PDH}$ enzyme.

The GsPDH ${ }^{\mathrm{NADH}}$ and GsPDH $\mathrm{NADPH}^{\mathrm{N}}$ enzymes (henceforth designated $\mathrm{PDH}^{\mathrm{NADH}}$ and $\mathrm{PDH}^{\mathrm{NADPH}}$ ) were much more stable than their E. coli counterparts. As shown in Supplementary Fig. 1, the $G$ stearothermophilus enzymes retained $\sim 50 \%$ activity after $1 \mathrm{~h}$ incubation at $67^{\circ} \mathrm{C}$, whereas the E. coli $\mathrm{PDH}$ enzymes were completely inactivated at $50^{\circ} \mathrm{C}$.

A second key requirement of the purge valve design is the use of an NADH oxidase with high cofactor specificity. We chose NoxE from Lactococcus lactis as it is a water-forming NADH oxidase so it does not generate any toxic products such as hydrogen peroxide $31,32,35$. As shown in Table 1 , the $K_{\text {cat }}$ of NoxE is 248.8 times greater with $\mathrm{NADH}$ than $\mathrm{NADPH}$ and $k_{\text {cat }} / K_{\mathrm{m}}$ is 9,900 times greater.

Enzyme catalysed production of PHB from pyruvate. The enzymes chosen for use in this work are listed in Table 1. In the initial tests, we only employed the WT, $\mathrm{PDH}^{\mathrm{NADH}}$ complex and NoxE to generate acetyl-CoA and supplied NADPH exogenously. After optimizing enzyme ratios in this simple system, we then added the mutant $\mathrm{PDH} \mathrm{NADPH}^{\mathrm{N}}$ to test in situ generation of NADPH. Finally, the amount of $\mathrm{PDH}^{\mathrm{NADPH}}$ was optimized, keeping the other enzymes fixed.

The progress of the optimized pyruvate to $\mathrm{PHB}$ reaction is shown in Fig. 3 along with a control lacking the last enzyme, phaC. Both reactions had a $\mathrm{PDH}^{\mathrm{NADPH}}: \mathrm{PDH}^{\mathrm{NADH}}$ ratio of $40: 1$. At this ratio, the NADPH levels rise rapidly $\left(\mathrm{A}_{340}\right)$ and are maintained throughout the time course (NoxE rapidly oxidizes $\mathrm{NADH}$ so changes in $\mathrm{A}_{340}$ reflect only changes in NADPH levels).
At the same time, $\mathrm{PHB}$ granules are produced as monitored by $\mathrm{A}_{600}$ (ref. 36).

We assayed the PHB production using a gas chromatography method and found that the optimized reaction produced $2.45 \pm 0.5 \mathrm{mg} \mathrm{ml}^{-1}$ of $\mathrm{PHB}$ from $50 \mathrm{mM}$ pyruvate, which represents nearly complete conversion $(94 \pm 20 \%)$ of pyruvate to plastic. In the optimized system, we started with $0.5 \mathrm{mM}$ $\mathrm{NADP}^{+}$, so achieving $94 \%$ yield requires over 90 turnovers of the $\mathrm{NADP}^{+}$cofactor, indicating a high level of system sustainability.

The stability of the full system was assessed by mixing components together and then initiating the reaction at various time delays. The decrease in extent of the reaction is shown in Supplementary Fig. 2. We find that the extent of reaction remains $\sim 50 \%$ after 2 days.

Autoregulatory behaviour of purge valve. The regulatory behaviour of the purge valve is better seen at sub-optimal enzyme concentrations and ratios of $\mathrm{PDH}^{\mathrm{NADPH}}$ to $\mathrm{PDH}^{\mathrm{NADH}}$ that slow down the response time. In the optimized assay (40:1 mol ratio of $\mathrm{PDH}^{\mathrm{NADPH}}: \mathrm{PDH}^{\mathrm{NADH}}$ ), we observed a rapid rise in $\mathrm{NADPH}$ levels, which was sustained throughout. In the non-optimal systems shown in Fig. 4, the purge valve cannot respond as rapidly to drops in NADPH concentrations so we can observe variations in NADPH levels as the system develops. We still observe a rapid initial rise in NADPH levels, but as intermediates build up, the consumption starts to outstrip NADPH production. Eventually, the system compensates by generating higher levels of NADPH. The restoration of NADPH levels would be impossible without the proper operation of the purge valve system.

The system is robust to cofactor levels. To test whether the system was robust to changes in cofactor levels, we varied the initial cofactor concentrations in the reactions and measured the yields of PHB. Each reaction was constructed with combinations of $\mathrm{NAD}^{+}, \mathrm{NADH}, \mathrm{NADP}^{+}$or NADPH at either 0.1 or $1 \mathrm{mM}$ and the production of PHB was monitored by the final OD at $600 \mathrm{~nm}$. All of the reaction conditions were compared with the

Table 1 | Enzymes used in this work.

\begin{tabular}{|c|c|c|c|c|c|c|c|}
\hline & Enzyme & Name & Accession number & Plasmid & Tag & Organism & Reference \\
\hline \multicolumn{8}{|c|}{ Purge valve } \\
\hline 1 & $\mathrm{PDH}^{\mathrm{NADH}}$ & Pyruvate dehydrogenase complex & & & & G. stearothermophilus & \\
\hline $1^{\prime}$ & PDH ${ }^{N A D P H}$ & & & & & & \\
\hline $1 \mathrm{a}$ & Ela & Pyruvate deyhdrogenase subunit a & P21873 & pET28 & None & G. stearothermophilus & This study \\
\hline $1 b$ & E1b & Pyruvate deyhdrogenase subunit $b$ & P21874 & pET28 & None & G. stearothermophilus & This study \\
\hline 1c & E2 & Dihydrolipoamide acetyltransferase & CAA37630 & pET22 & None & G. stearothermophilus & This study \\
\hline $1 d$ & $\mathrm{E}^{\mathrm{NADH}}$ & Dihydrolipoamide dehydrogenase & P11959 & pET28 & None & G. stearothermophilus & This study \\
\hline $1^{\prime} d$ & E3 $3^{N A D P H}$ & Mutant dihydrolipoamide dehydrogenase & P11959 & pET29 & None & G. stearothermophilus & This study \\
\hline $1 e$ & LplA & Lipoate protein ligase & NP_418803 & $\mathrm{pBAD} / \mathrm{p} 15 \mathrm{~A}$ & $\mathrm{~N}$-His & E. coli & This study \\
\hline 2 & NoxE & NADH oxidase (H2O forming) & YP_007507681 & pET22 & C-His & L. lactis & This study \\
\hline \multicolumn{8}{|c|}{ PHB pathway } \\
\hline 3 & PhaA & Acetyl-CoA acetyltransferase & GJUJ-1435 & pET28 & $\mathrm{N}$-His & R. eutropha & This study \\
\hline 4 & PhaB & 3-Hydroxybutryl-CoA reductase & GJUJ-1436 & pET28 & $\mathrm{N}$-His & R. eutropha & This study \\
\hline 5 & PhaC & Polyhydroxybutyrate synthase & G8BLJ2 & pET28 & $\mathrm{N}-\mathrm{His}$ & C. necator sp. S-6 & This study \\
\hline \multicolumn{8}{|c|}{ Isoprene pathway } \\
\hline 6 & $\mathrm{THL} / \mathrm{HMGR}$ & Thiolase/HMG-CoA reductase fusion & WP_002357755 & pET28 & $\mathrm{N}$-His & E. faecalis & 30 \\
\hline 7 & HMGS & HMG-CoA synthase A110G mutant & WP_010785222 & pET28 & $\mathrm{N}$-His & E. faecalis & 30 \\
\hline 8 & HMGR & HMG-CoA reductase & WP_002357755 & pET28 & $\mathrm{N}$-His & E. faecalis & 30 \\
\hline 9 & MVK & Mevalonate kinase & BAA24409 & pET28 & $\mathrm{N}$-His & S. cerevisiae & 30 \\
\hline 10 & PMVK & Phosphomevalonate kinase & NP_344303 & pET28 & $\mathrm{N}$-His & S. solfataricus & 30 \\
\hline 11 & MDC & Diphosphomevalonate decarboxylase & NP_014441 & pET28 & $\mathrm{N}$-His & S. cerevisiae & 30 \\
\hline 12 & Idi & Isopentenyl diphosphate isomerase & NP_417365 & pET22 & $\mathrm{C}-\mathrm{His}$ & E. coli & 30 \\
\hline 13 & IspS & Isoprene synthase & Q50L36 & pET28 & $\mathrm{N}-\mathrm{His}$ & P. alba & 30 \\
\hline
\end{tabular}






Figure 3 | Production of PHB using an optimized system. In this reaction, the production of PHB is monitored by an increase $A_{600}$ (blue) caused by precipitation of the PHB granules. No increase is seen in the absence of the PHB polymerase, PhaC. The production of PHB is confirmed by a gas chromatography assay (see text). The $A_{340}$ (red) monitors the level of NADPH because no NADH is allowed to build up because of the presence of NoxE. The purge valve system maintains a high level of NADPH throughout the reaction.

optimized reaction that produced nearly complete conversion of pyruvate to $\mathrm{PHB}$ and, as shown in Fig. 5, were within random variation (see also Supplementary Table 3 ). This result indicates that the purge valve can compensate readily for changes in cofactor concentrations and reduction states.

Porting the purge valve system to isoprene production. To test the versatility of the molecular purge valve and whether it can be applied as a general platform for the production of a diverse array of acetyl-CoA-derived compounds, we used the $\mathrm{PDH}$ purge valve to produce isoprene via the acetyl-CoA-dependent mevalonate pathway. We have previously described the in vitro production of isoprene from pyruvate, which required the use of exogenously added $\mathrm{NADPH}^{30}$. Similar to the PHB pathway, the mevalonate pathway has an inherently different carbon and cofactor stoichiometry. In particular, the mevalonate pathway requires three acetyl-CoA and two NADPH for the production of isoprene (see Fig. 6a). Thus, system sustainability requires generation and regulation of NADPH levels.

We tested whether the purge valve system can replace exogenously added NADPH in the production of isoprene. As shown in Fig. 6b, the full purge valve system produces an $88.2 \pm 8.4 \%$ yield from $3 \mathrm{mM}$ pyruvate. This yield is even higher than the $81.4 \pm 2.0 \%$ yield obtained if we add NADPH exogenously (Fig. 6b). If we leave out any of the purge valve components $\left(\mathrm{PDH} \mathrm{NADPH}^{\mathrm{NADH}} \mathrm{PDHDH}^{\mathrm{NAD}}\right.$ or NoxE), yields are markedly reduced. Thus, the purge valve system is clearly transportable to other synthetic biochemistry systems.

\section{Discussion}

Maintaining proper cofactor balance is an essential part of generating flux and providing a driving force through an enzymatic pathway. In vivo, the enzymatic specificity for the cofactors NADH and NADPH are typically used to control the carbon flux through catabolic and anabolic pathways, respectively. Organisms typically sense the reduction state of these cofactors and use this information to upregulate or downregulate

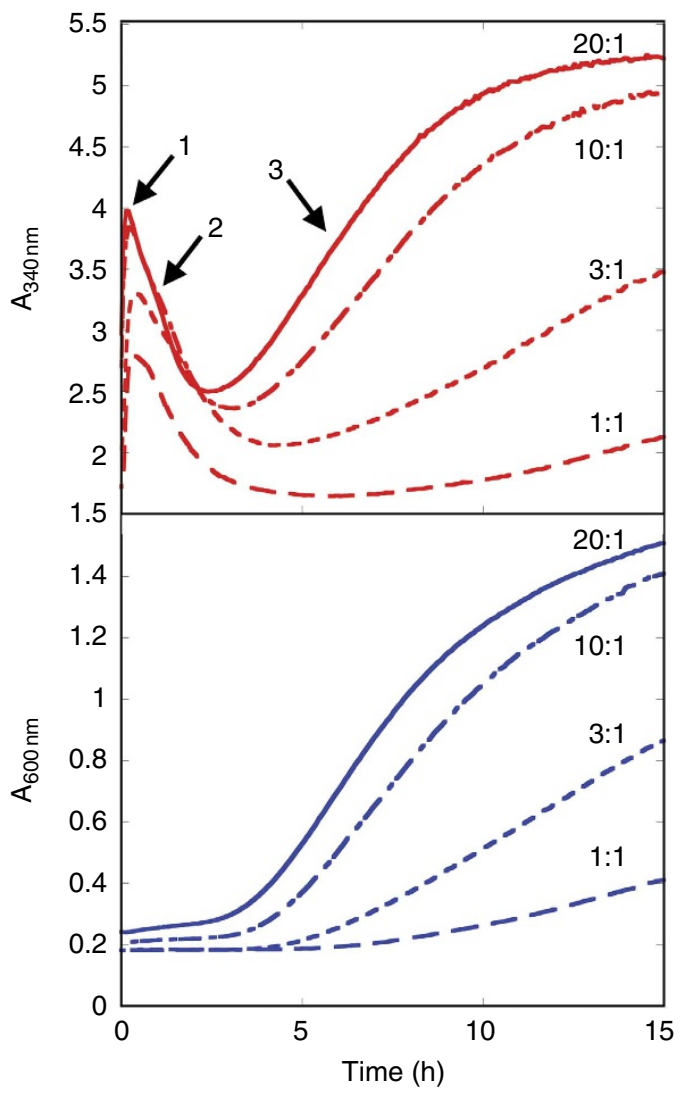

Figure 4 | Time course of pyruvate to PHB optimization reaction using sub-optimal ratios of $\mathbf{P D H} \mathbf{N A D P H}^{\mathbf{N}}$ and $\mathbf{P D H} \mathbf{N A D H}^{\mathbf{N}}$. The $A_{340}$ traces (red), monitoring NADPH levels fall into three distinct phases. A fast initial reduction of NADPH by the $\mathrm{PDH}^{\mathrm{NADPH}}$ is followed by a slow oxidation of $\mathrm{NADPH}$ by $\mathrm{PhaB}$ as the intermediate levels rise. As the reaction proceeds, the purge valve effectively turns off and NADPH levels rise again. The evolution of the system coincides with the increase at $A_{600}$ (blue), which represents the precipitation of the PHB granules from solution.

catabolic and anabolic pathways to cope with environmental changes. In vitro systems, however, do not have the myriad peripheral pathways that facilitate this fine control. Moreover, the natural anabolic and catabolic specificities for $\mathrm{NADH}$ and NADPH complicate in vitro biotransformations. Synthetic biochemistry systems have often dealt with these problems by careful considerations of cofactor stoichiometry in pathway design, through the use of expensive sacrificial metabolites, reengineering enzymes so that only a single cofactor type is needed, adding excess cofactors, or constantly adding intermediates to the reaction mix to sustain the process.

In this work, we created a robust node of control to balance the production and consumption of NADPH and NADH in a selfregulating and self-balancing manner. To our knowledge, this is the first in vitro pathway that maintains cofactor balance without requiring adherence to stoichiometry in the generation and utilization of cofactors to ensure carbon flux. In part because the system can sustain high levels of NADPH, we can drive the transformation to near completion, converting pyruvate to either PHB or isoprene at nearly $100 \%$ of the theoretical yield. Moreover, the high yields in our system are robust to 10 -fold variations in cofactor levels.

Ultimately it will be necessary to expand this pathway to incorporate the conversion of low-cost substrates such as glucose or other sugars into pyruvate, which would involve the glycolysis pathway or parts of the glycolysis pathway. Indeed a synthetic 




Figure $\mathbf{5}$ | The purge valve system is robust. The graph shows relative yield of PHB upon starting with different amounts of each of the cofactors. The relative yields represent the ratio of the final $A_{600}$ for the reaction, relative to the final $A_{600}$ for the optimized reaction. All reactions show a relatively robust yield in comparison with the negative control lacking the final phaC enzyme (orange bar). The error bars reflect the s.d. of three independent reactions. The data are listed in Supplementary Table 3.

biochemistry system employing glycolysis has been demonstrated previously ${ }^{5}$. Building more complex compounds from acetyl-CoA such as fatty acids, polyketides and other isoprenoids will also require the incorporation and recycling of ATP. Thus, it would be desirable to develop simple methods to regulate the ATP/ADP levels within the context of synthetic biochemistry. ATP regulation will be an interesting challenge for future synthetic biochemistry pathway designs. Ultimately, developing regulatory systems similar to the purge valve employed here will free synthetic biochemistry system design from having to consume the high-energy cofactors during the anabolic phase in perfect stoichiometric balance. Thus, our approach can help diversify the chemical targets of synthetic biochemistry.

\section{Methods}

Materials. Miller Luria-Bertani (LB) media or Miller LB-agar (BD Difco) was used for growth of bacterial strains in liquid or solid media. E. coli BL21-Gold(DE3) (B, F-, ompT, $h s d S_{\mathrm{B},}\left(\mathrm{r}_{\mathrm{B}}-, \mathrm{m}_{\mathrm{B}}-\right), d c m+, T e t^{r}, g a l \lambda$, (DE3) endA Hte) (Agilent) was used as a host for both cloning and expression of recombinant proteins using $\mathrm{pET}$ vectors. E. coli TOP10(DE3) (F- mcrA $\Delta$ (mrr-hsdRMS-mcrBC) $\phi 80$ lacZ $\Delta$ M15 $\Delta$ lacX74 nupG recA1 araD139 $\Delta$ (ara-leu)7697 galE15 galK16 $\operatorname{rpsL}\left(\mathrm{Str}^{\mathrm{R}}\right)$ endA1 $\lambda^{-}$) was used for expression of recombinant proteins from the $\mathrm{pBAD} / \mathrm{p} 15 \mathrm{~A}$ vector ${ }^{37}$. Plasmids pET28a $(+)$ and pET22b $(+)$ were purchased from Novagen. HotStart Taq Mastermix (Denville) was used for gene amplification from genomic or plasmid DNA. Phusion DNA polymerase (Finnizymes), Taq DNA ligase (MCLab), and T5 Exonuclease (Epicenter) were purchased separately and used to make the assembly master mix (AMM) used for cloning (ref). ATP, $( \pm)$ - $\alpha$-lipoic acid, pyruvate, coenzyme A and $\mathrm{NAD}^{+}$were from Sigma.

Plasmid construction. The expression plasmids for the PHB enzymes were constructed from the pET28a plasmid backbone using the Nde1- and Sac1-cut sites to produce constructs with an N-terminal $6 \times$ His tag for purification. The genes encoding acetyl-CoA acetyltraferase (phaA; YP_725941) and acetoacetyl-CoA reductase (phaB; YP_725942) ${ }^{23}$ were amplified and cloned from Ralstonia eutropha genomic DNA. The gene encoding PHB synthase ${ }^{38,39}$ (phaC; HE_610111) was synthesized and codon optimized for expression in an E. coli host at Life Technologies before being subcloned into the pET28a expression vector. For the isoprene pathway, the constructs were the same as described in reference ${ }^{30}$.

E. coli BL21-Gold cells were used as the host strain for enzyme expression. All enzymes were expressed in LB media supplemented with $50 \mu \mathrm{g} \mathrm{ml}^{-1}$ kanamycin
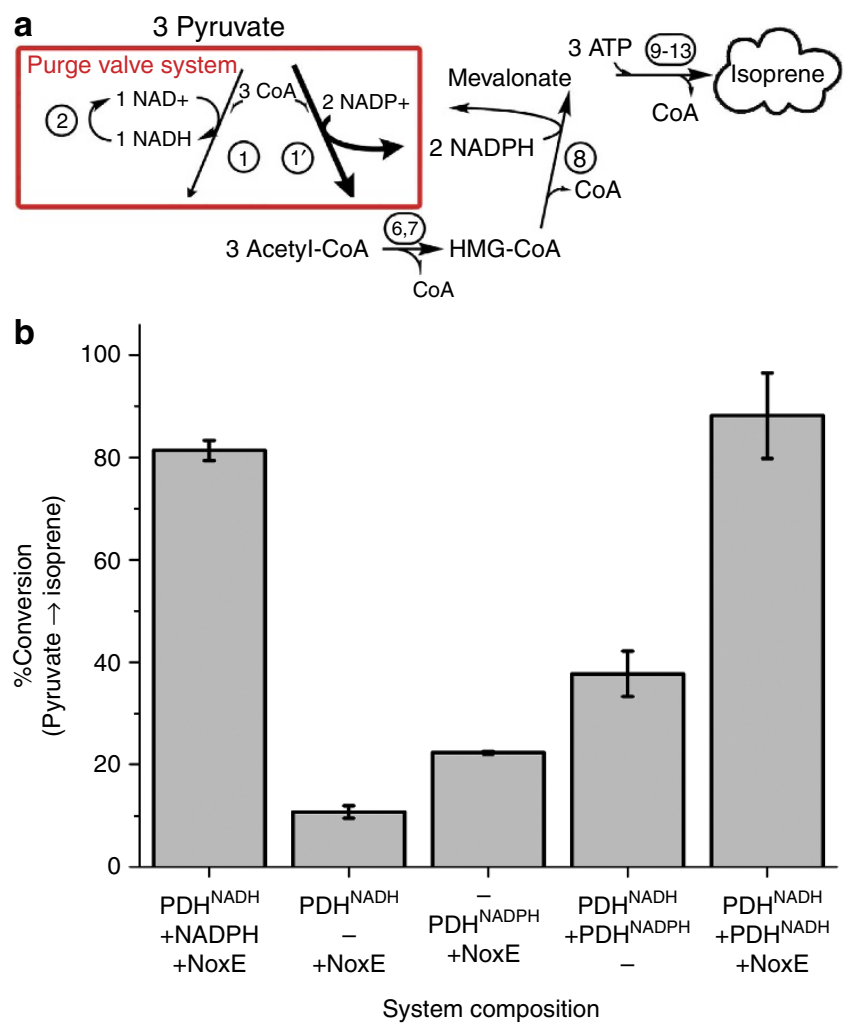

Figure 6 | Employing the purge valve for the production of isoprene. (a) The in vitro metabolic pathway for the conversion of pyruvate to isoprene. The purge valve highlighted in the red box consists of the same enzymes/reactions as in Fig. 1. In the mevalonate pathway, three acetylCoA are used to make HMG-CoA (enzymes 6 and 7). HMG-CoA is reduced by HMGR (enzyme 8) with two NADPH to give mevalonate. Three ATP are then used to convert mevalonate to isopentenyl pyrophosphate followed by production of isoprene (enzymes 9-13). (b) The graph shows the dependence of isoprene production on the purge valve. No purge valve was used in the first reaction (PDH ${ }^{N A D H}, \mathrm{NADPH}$ and NoxE). NADPH was simply added and NADH recycled using NoxE. The final experiment $\left(\mathrm{PDH}^{\mathrm{NADH}}, \mathrm{PDH}^{\mathrm{NADPH}}\right.$ and NoxE) shows results employing the full purge valve system. Leaving out any component of the purge valve system resulted in marked decreases in isoprene production. Each reaction was performed in duplicate and the error was calculated as the s.d. of the two replicates.

and were induced with $0.2 \mathrm{mM}$ isopropyl- $\beta$-D-1-thiogalactopyranoside added to the culture at the end of log phase growth. The phaA, phaB, MVK, PMVK and IspS were induced at $37^{\circ} \mathrm{C}$ overnight and phaB, THL/HMGR, HMGS and IDI were induced at $18^{\circ} \mathrm{C}$ overnight. The phaC was induced at $25^{\circ} \mathrm{C}$ for $5 \mathrm{~h}$ before harvesting.

Enzyme purification. Cells from 0.51 of culture were harvested by centrifugation and resuspended in $150 \mathrm{mM}$ Tris $\mathrm{pH} 7.5,100 \mathrm{mM} \mathrm{NaCl}$. The cells were lysed on ice with sonication and the cell debris was removed by $12,000 \mathrm{~g}$ centrifugation at $4{ }^{\circ} \mathrm{C}$. The supernatant was then mixed with $5 \mathrm{ml}$ nickel-nitrilotriacetic acid agarose and after $30 \mathrm{~min}$, the agarose slurry was loaded onto a gravity column and washed with five-column volumes of $100 \mathrm{mM}$ Tris $\mathrm{pH} 7.5,100 \mathrm{mM} \mathrm{NaCl}$ and $15 \mathrm{mM}$ imidazole. The enzyme was then eluted with $250 \mathrm{mM}$ imidazole, $100 \mathrm{mM}$ Tris $\mathrm{pH} 7.5$. The resulting enzyme was dialysed into $50 \mathrm{mM}$ Tris $\mathrm{pH} 7.5,50 \mathrm{mM} \mathrm{NaCl}$ and stored at $4^{\circ} \mathrm{C}$.

Expression vectors for PDH subunits and E. coli LpIA. The E1, E2 and E3 domains were all amplified separately from G. stearothermophilus genomic DNA (ATCC) using primers that contained $15-20 \mathrm{bp}$ complementary to the gene and 15-20 bp complementary to the multiple cloning site in the vector where the gene would be placed. The genes encoding $\mathrm{E} 1 \alpha$ and $\mathrm{E} 1 \beta$ were amplified together from G. stearothermophilus genomic DNA and cloned into pET28a $(+)$ that had been digested with $\mathrm{NcoI}$ and $\mathrm{XhoI}$. This created a tagless construct for E1 expression under control of the T7 promoter where E1 $\alpha$ translation uses the ribosomal 
binding site from the pET28 vector while E1 $\beta$ uses the endogenous ribosomal binding site from G. stearothermophilus. The E2 and E3 domains were amplified separately and cloned into pET22b(+) digested with $N d e I$ and XhoI or pET28a ( + ) digested with NcoI and XhoI, respectively, to create tagless E2 and E3 constructs. The E. coli lipoate protein ligase, LplA, was amplified from E. coli K12 genomic DNA and assembled into $\mathrm{pBAD} / \mathrm{p} 15 \mathrm{~A}^{37}$ digested with $\mathrm{XhoI}$ and $E c o \mathrm{RI}$ to create $6 \times$ His-LplA.

Overexpression and purification of PDH subunits and LpIA. All E. coli strains were grown at $37^{\circ} \mathrm{C}$ in LB-media supplemented with appropriate antibiotic (100 $\mu \mathrm{g} \mathrm{ml}^{-1}$ ampicillin, $50 \mu \mathrm{g} \mathrm{ml}^{-1}$ kanamycin or $34 \mu \mathrm{g} \mathrm{ml}^{-1}$ chloramphenicol). For all constructs, $5 \mathrm{ml}$ of overnight starter culture was used to inoculate 11 of LB-media. Once the $\mathrm{OD}_{600}$ reached $0.6,0.3 \mathrm{mM}$ IPTG (pET vectors) or $0.02 \%$ arabinose (pBAD/p15A) was added to induce protein expression. After $16 \mathrm{~h}$, cells were harvested, resuspended $\left(4 \mathrm{mlg}^{-1}\right.$ wet cells) in $50 \mathrm{mM}$ Tris-Cl pH 7.5, $0.1 \mathrm{M}$ $\mathrm{NaCl}$ (buffer A), lysed by sonication and cell debris removed by centrifugation at $30,000 \mathrm{~g}$ for $20 \mathrm{~min}$.

E. coli lysate $(25 \mathrm{ml})$ containing $6 \times$ His-LplA was loaded onto a $3-\mathrm{ml}$ nickelnitrilotriacetic acid resin (Qiagen), washed with $25 \mathrm{ml}$ buffer A containing $10 \mathrm{mM}$ imidazole and eluted with $5 \mathrm{ml}$ buffer A containing $250 \mathrm{mM}$ imidazole. Pure $6 \times$ His-LplA was then stored at $4{ }^{\circ} \mathrm{C}$ until use.

The individual domains of G. stearothermophilus PDH were partially purified from E. coli lysates by heat before modification and reconstitution of the PDH complex. E1 $\alpha \beta$-, E2- or E3-containing lysates were incubated at $65^{\circ} \mathrm{C}$ for $35 \mathrm{~min}$ to heat denature E. coli proteins followed by centrifugation at $30,000 \mathrm{~g}$ for $20 \mathrm{~min}$ to pellet the precipitated proteins. Nearly all of the PDH domains remain in the supernatant. Next, the E2 domain was lipoated in the heated extract by the addition of $1 \mathrm{mM}( \pm)$ - $\alpha$-lipoic acid, $2 \mathrm{mM}$ ATP, $3 \mathrm{mM} \mathrm{MgCl}_{2}$ and $50 \mu \mathrm{g}$ of purified $6 \times$ His-LplA. The lipoation reaction was then allowed to proceed with gentle mixing overnight at $25^{\circ} \mathrm{C}$, yielding lipoated E2 (E2lip). After lipoation, E1 $\alpha \beta$, E2lip and E3 were mixed in a 3:1:3 molar ratio and incubated for at least $1 \mathrm{~h}$ at $25^{\circ} \mathrm{C}$ to form the active GsPDH complex. The GsPDH complex was then isolated by ultracentrifugation (Beckman) for $4 \mathrm{~h}$ at $95,000 \mathrm{~g}$. The resulting yellow pellet was resuspended in $20 \mathrm{mM}$ Tris-Cl, pH 7.5 in 1/50 the starting volume and assayed for activity $^{33,34,40}$. SDS-polyacrylamide gel electrophoresis analysis confirmed the presence of all four domains and indicated that the preparation was $>90 \%$ pure. The reconstituted complex was stored at $4{ }^{\circ} \mathrm{C}$ until use.

Enzyme activity and optimization. NoxE was assayed by monitoring the oxidation of $\mathrm{NAD}(\mathrm{P}) \mathrm{H}$ at $340 \mathrm{~nm}$. The assay was carried out in $100 \mathrm{mM}$ Tris- $\mathrm{HCl}$ $\mathrm{pH} 7.5,5 \mathrm{mM} \mathrm{MgCl}_{2}, 5 \mathrm{mM} \mathrm{KCl}$ and $0.2 \mathrm{mM} \mathrm{NAD}(\mathrm{P}) \mathrm{H}$.

WT and mutant PDH were assayed by monitoring the reduction of NAD(P) ${ }^{+}$ at $340 \mathrm{~nm}$. The assay was carried out in $50 \mathrm{mM}$ Tris $\mathrm{pH} 7.5,5 \mathrm{mM} \mathrm{MgCl}_{2}, 5 \mathrm{mM}$ pyruvate, $1 \mathrm{mM} \mathrm{CoA}$ and $0.5 \mathrm{mM}$ of $\mathrm{NAD}(\mathrm{P})^{+}$.

PhaC was assayed by monitoring the absorbance of the hydrolysis of the thioester bond of the substrate $3 \mathrm{HBCoA}$ at $235 \mathrm{~nm}$. The assay was carried out in $100 \mathrm{mM}$ Tris pH 7.5, $5 \mathrm{mM} \mathrm{MgCl}_{2}$ and $0.15 \mathrm{mM} 3 \mathrm{HBCoA}$.

Activity of NADPH-consuming isoprene pathway enzymes were monitored with the decrease of absorbance at $340 \mathrm{~nm}$. Activity of ATP-consuming enzymes were monitored with a coupled assay system with pyruvate kinase and lactate dehydrogenase at $340 \mathrm{~nm}$. The amount of each enzyme in the reconstituted isoprene pathway described below is show in Supplementary Table 2.

Final PHB reaction conditions and analysis. The optimized self-sustaining reaction for the biotransformation of pyruvate to PHB was composed of $250 \mathrm{mM}$ Tris $\mathrm{pH} 7.5,5 \mathrm{mM} \mathrm{MgCl}, 5 \mathrm{mM} \mathrm{KCl}, 0.5 \mathrm{mM} \mathrm{CoA}, 0.1 \mathrm{mM} \mathrm{NAD}^{+}, 0.5 \mathrm{mM}$ $\mathrm{NADP}^{+}, 50 \mathrm{mM}$ pyruvate, $2 \mu \mathrm{g} \mathrm{PDH}^{\mathrm{NADH}}, 76 \mu \mathrm{g} \mathrm{PDH}^{\mathrm{NADPH}}, 23 \mu \mathrm{g}$ phaA, $14 \mu \mathrm{gphaB}$ and $32 \mu \mathrm{g} \mathrm{phaC}$ in a final reaction volume of $200 \mu \mathrm{l}$. The reactions were initiated with the addition of pyruvate, which was left out of the initial mixture. All $\mathrm{PHB}$ reactions were performed at room temperature. For testing the autoregulatory behaviour of the purge valve, some enzyme concentrations were sub-optimal: $5 \mu \mathrm{g}$ phaA, $2.5 \mu \mathrm{g} \mathrm{phaB}$ and $1.9 \mu \mathrm{g} \mathrm{phaC}$

To assay for PHB, the reactions were lyophilized and incubated with $1 \mathrm{ml}$ chloroform, $0.45 \mathrm{ml}$ methanol and $0.05 \mathrm{ml} \mathrm{H}_{2} \mathrm{SO}_{4}$ to hydrolyse the polymer and generate methyl 3-hydroxybutyrate. The reactions were extracted with $0.5 \mathrm{ml}$ water and $1 \mu \mathrm{l}$ of the chloroform layer was applied to a 0.25 -micron HP-Innowax column using a HP 5890 Series II gas chromatogram. The gas chromatography method used an injection temperature that was held at $35^{\circ} \mathrm{C}$ for $5 \mathrm{~min}$ before it was increased to $275^{\circ} \mathrm{C}$ over $40 \mathrm{~min}$. The peak intensities were compared with an authentic standard to assess concentrations.

Isoprene reaction conditions and analysis. In vitro production of isoprene was performed as described previously ${ }^{30}$ with the following changes. $200 \mu$ l reactions were set up in 2-ml gas-tight vials containing enzymes, $3 \mathrm{mM}$ pyruvate, $15 \mathrm{mM}$ ATP, $0.6 \mathrm{mM} \mathrm{CoA}, 0.2 \mathrm{mM} \mathrm{NAD}+, 0.4 \mathrm{mM} \mathrm{NADP}+$ (or $5 \mathrm{mM} \mathrm{NADPH}$ ), $10 \mathrm{mM} \mathrm{MgCl}_{2}, 20 \mathrm{mM} \mathrm{KCl}$ and $0.1 \mathrm{mM}$ thiamine pyrophosphate in $100 \mathrm{mM}$ Tris$\mathrm{Cl} \mathrm{pH} 8.5$ and incubated at $32^{\circ} \mathrm{C}$ for $18 \mathrm{~h}$. Isoprene production was monitored by direct sampling of $100 \mu \mathrm{l}$ of the headspace using a 100- $\mu \mathrm{l}$ gas-tight syringe. The headspace was analysed by GC-FID (HP5980II) equipped with a GS-GasPro column $(0.32 \mathrm{~mm} \times 30 \mathrm{~m}$, Agilent $)$ as described previously ${ }^{30}$. The carrier gas was helium with a flow rate of $5 \mathrm{ml} \mathrm{min}-1$. The oven temperature was kept at $120^{\circ} \mathrm{C}$ for $3 \mathrm{~min}$ then raised to $230^{\circ} \mathrm{C}$ at $5 \mathrm{C} \mathrm{min}^{-1}$ then to $250^{\circ} \mathrm{C}$ at $20^{\circ} \mathrm{C} \mathrm{min}^{-1}$ and held for at $250^{\circ} \mathrm{C}$ for $9 \mathrm{~min}$. The inlet and detector temperatures were kept at 270 and $330^{\circ} \mathrm{C}$, respectively. The amount of isoprene produced was quantified by comparison with a standard curve of various isoprene concentrations sampled in the same manner.

\section{References}

1. Zhang, Y. H. P. Simpler is better: high-yield and potential low-cost biofuels production through cell-free synthetic pathway biotransformation (SyPaB). ACS Catal. 1, 998-1009 (2011).

2. Hold, C. \& Panke, S. Towards the engineering of in vitro systems. J. R. Soc Interface 6 (Suppl 4) S507-S521 (2009).

3. Rollin, J. A., Tam, T. K. \& Zhang, Y. H. P. New biotechnology paradigm: cellfree biosystems for biomanufacturing. Green Chem. 15, 1708-1719 (2013).

4. Algar, E. M. \& Scopes, R. K. Studies on cell-free metabolism-ethanolproduction by extracts of zymomonas-mobilis. J. Biotechnol. 2, 275-287 (1985).

5. Welch, P. \& Scopes, R. K. Studies on cell-free metabolism-ethanol-production by a yeast glycolytic system reconstituted from purified enzymes. J. Biotechnol. 2, 257-273 (1985).

6. Bujara, M., Schumperli, M., Billerbeek, S., Heinemann, M. \& Panke, S. Exploiting cell-free systems: implementation and debugging of a system of biotransformations. Biotechnol. Bioeng. 106, 376-389 (2010).

7. Bujara, M., Schumperli, M., Pellaux, R., Heinemann, M. \& Panke, S. Optimization of a blueprint for in vitro glycolysis by metabolic real-time analysis. Nat. Chem. Biol. 7, 271-277 (2011).

8. Ye, X. et al. Synthetic metabolic engineering-a novel, simple technology for designing a chimeric metabolic pathway. Microb. Cell. Fact. 11, 120 (2012).

9. Ye, X., Honda, K., Morimoto, Y., Okano, K. \& Ohtake, H. Direct conversion of glucose to malate by synthetic metabolic engineering. J. Biotechnol. 164, 34-40 (2013).

10. Yu, X. Y., Liu, T. G., Zhu, F. Y. \& Khosla, C. In vitro reconstitution and steadystate analysis of the fatty acid synthase from Escherichia coli. Proc. Natl Acad. Sci. USA 108, 18643-18648 (2011).

11. Jewett, M. C. \& Swartz, J. R. Rapid expression and purification of $100 \mathrm{nmol}$ quantities of active protein using cell-free protein synthesis. Biotechnol. Prog. 20, 102-109 (2004).

12. Jewett, M. C., Calhoun, K. A., Voloshin, A., Wuu, J. J. \& Swartz, J. R. An integrated cell-free metabolic platform for protein production and synthetic biology. Mol. Syst. Biol. 4, 220 (2008).

13. Schultheisz, H. L., Szymczyna, B. R., Scott, L. G. \& Williamson, J. R. Pathway engineered enzymatic de novo purine nucleotide synthesis. ACS Chem. Biol. $\mathbf{3}$, 499-511 (2008)

14. Schultheisz, H. L., Szymczyna, B. R., Scott, L. G. \& Williamson, J. R. Enzymatic de novo pyrimidine nucleotide synthesis. J. Am. Chem. Soc. 133, 297-304 (2011).

15. Zhang, Y. H. P., Evans, B. R., Mielenz, J. R., Hopkins, R. C. \& Adams, M. W. W. High-yield hydrogen production from starch and water by a synthetic enzymatic pathway. PLoS ONE 2, e456 (2007).

16. Ye, X. H. et al. Spontaneous high-yield production of hydrogen from cellulosic materials and water catalyzed by enzyme cocktails. ChemSusChem 2, 149-152 (2009).

17. Woodward, J., Orr, M., Cordray, K. \& Greenbaum, E. Biotechnologyenzymatic production of biohydrogen. Nature 405, 1014-1015 (2000)

18. Krutsakorn, B. et al. In vitro production of n-butanol from glucose. Metab. Eng. 20, 84-91 (2013).

19. Guterl, J. K. et al. Cell-free metabolic engineering: production of chemicals by minimized reaction cascades. ChemSusChem 5, 2165-2172 (2012).

20. Chen, G.-Q. in Plastics from Bacteria: Natural Functions and Application Vol. 14 Microbiology Monographs. (ed Chen, G. Q.) 121-132 (Springer, 2010).

21. Kawada, J., Lutke-Eversloh, T., Steinbuchel, A. \& Marchessault, R. H. Physical properties of microbial polythioesters: characterization of poly(3-mercaptoalkanoates) synthesized by engineered Escherichia coli. Biomacromolecules 4, 1698-1702 (2003).

22. Dawes, E. A. Polyhydroxybutyrate-an intriguing bio-polymer. Biosci. Rep. 8, 537-547 (1988)

23. Satoh, Y., Tajima, K., Tannai, H. \& Munekata, M. Enzyme-catalyzed poly(3-hydroxybutyrate) synthesis from acetate with CoA recycling and NADPH regeneration in vitro. J. Biosci. Bioeng. 95, 335-341 (2003).

24. Yang, J. et al. Enhancing production of bio-isoprene using hybrid MVA pathway and isoprene synthase in E. coli. PLoS ONE 7, e33509 (2012).

25. Kesselmeier, J. \& Staudt, M. Biogenic volatile organic compounds (VOC): an overview on emission, physiology and ecology. J. Atmos. Chem. 33, 23-88 (1999).

26. Lindberg, P., Park, S. \& Melis, A. Engineering a platform for photosynthetic isoprene production in cyanobacteria, using Synechocystis as the model organism. Metab. Eng. 12, 70-79 (2010). 
27. Peralta-Yahya, P. P., Zhang, F. Z., del Cardayre, S. B. \& Keasling, J. D. Microbial engineering for the production of advanced biofuels. Nature 488, 320-328 (2012).

28. Yang, J. M. et al. Bio-isoprene production using exogenous MVA pathway and isoprene synthase in Escherichia coli. Bioresour. Technol. 104, 642-647 (2012).

29. Xue, J. \& Ahring, B. K. Enhancing isoprene production by genetic modification of the 1-deoxy-D-xylulose-5-phosphate pathway in Bacillus subtilis. Appl. Environ. Microbiol. 77, 2399-2405 (2011).

30. Korman, T. P. et al. A synthetic biochemistry system for the in vitro production of isoprene from glycolysis intermediates. Protein Sci. 23, 576-585 (2014).

31. Kawasaki, S., Ishikura, J., Chiba, D., Nishino, T. \& Niimura, Y. Purification and characterization of an $\mathrm{H} 2 \mathrm{O}$-forming $\mathrm{NADH}$ oxidase from Clostridium aminovalericum: existence of an oxygen-detoxifying enzyme in an obligate anaerobic bacteria. Arch. Microbiol. 181, 324-330 (2004).

32. Geueke, B., Riebel, B. \& Hummel, W. NADH oxidase from Lactobacillus brevis: a new catalyst for the regeneration of NAD. Enzyme Microb. Technol. 32, 205-211 (2003).

33. Bocanegra, J. A., Scrutton, N. S. \& Perham, R. N. Creation of an nadpdependent pyruvate-dehydrogenase multienzyme complex by protein engineering. Biochemistry 32, 2737-2740 (1993).

34. Richter, N., Zienert, A. \& Hummel, W. A single-point mutation enables lactate dehydrogenase from Bacillus subtilis to utilize $\operatorname{NAD}(+)$ and $\operatorname{NADP}(+)$ as cofactor. Eng. Life Sci. 11, 26-36 (2011).

35. Gao, H., Tiwari, M. K., Kang, Y. C. \& Lee, J. K. Characterization of $\mathrm{H} 2 \mathrm{O}$-forming $\mathrm{NADH}$ oxidase from Streptococcus pyogenes and its application in L-rare sugar production. Bioorg. Med. Chem. Lett. 22, 1931-1935 (2012).

36. Gerngross, T. \& Martin, D. Enzyme-catalyzed synthesis of poly [(R)-(-)-3-hydroxybutyrate]: formation of macroscopic granules in vitro. Proc. Natl Acad. Sci. USA 92, 6279-6283 (1995).

37. Massey-Gendel, E. et al. Genetic selection system for improving recombinant membrane protein expression in E-coli. Protein Sci. 18, 372-383 (2009).
38. Rehm, B. H. A. Polyester synthases: natural catalysts for plastics. Biochem. J. 376, 15-33 (2003).

39. Sheu, D. S., Chen, W. M., Lai, Y. W. \& Chang, R. C. Mutations derived from the thermophilic polyhydroxyalkanoate synthase $\mathrm{PhaC}$ enhance the thermo stability and activity of PhaC from Cupriavidus necator H16. J. Bacteriol. 194, 2620-2629 (2012).

40. Kim, D. J. et al. Crystal structure of lipoate-protein ligase A bound with the activated intermediate-Insights into interaction with lipoyl domains. J. Biol. Chem. 280, 38081-38089 (2005).

\section{Acknowledgements}

We thank members of the Bowie lab for critical reading of this manuscript. The work was supported by the DOE grant DE-FC02-02ER63421 to J.U.B.

\section{Author contributions}

P.H.O., T.P.K. and J.U.B. designed the experiments, analysed experimental results and wrote the maunscript. P.H.O. and T.P.K. conducted the experiments.

\section{Additional information}

Supplementary Information accompanies this paper at http://www.nature.com/ naturecommunications

Competing financial interests: The authors declare no competing financial interests

Reprints and permission information is available online at http://npg.nature.com/ reprintsandpermissions/

How to cite this article: Opgenorth, P. H. et al. A synthetic biochemistry molecular purge valve module that maintains redox balance. Nat. Commun. 5:4113 doi: $10.1038 /$ ncomms5113 (2014). 